\title{
Mobilizing greater crop and land potentials sustainably
}

\author{
Amir KASSAM ${ }^{1}$, GotTlieb BASCH${ }^{2}$, Theodor FRIEDRICH ${ }^{3}$, Emilio GONZALEZ ${ }^{3}$, \\ PAULA TRIVINO ${ }^{3}$ and SAIDI MKOMWA ${ }^{4}$
}

\begin{abstract}
The supply side of the food security engine is the way we farm. The current engine of conventional tillage farming is faltering and needs to be replaced. It is faltering because it causes unacceptable level of soil erosion and land degradation, and loss in yield potential, productivity, efficiency, resilience and ecosystem services. 'Business as usual' is no longer considered to be a suitable option for the future. This article addresses the supply side issues of agriculture to meet future agricultural demands for food and by industry with the alternate Conservation Agriculture (CA) paradigm (involving no-till seeding and weeding in soils with mulch cover and in diversified cropping) that is able to raise productivity sustainably and efficiently, reduce costly inputs, regenerate degraded land, minimize soil erosion, and harness the flow of ecosystem services. CA is an ecosystems approach to farming capable of enhancing not only the economic and environmental performance of crop production and land management, but also promotes a mindset change for producing 'more from less', the key attitude towards sustainable production intensification. CA is spreading globally in all continents at an annual rate of some 10 million hectares of cropland. In 2013-2014, CA covered more than 157 million hectares of rainfed and irrigated cropland and it is likely that its current spread is close to some 200 million hectares. In addition, perennial cropping systems such as orchards and plantations are being transformed into CA systems in all continents. In addition to being a best option for large-scale farmers, CA offers a real pro-poor agricultural development model to support sustainable agricultural intensification for low input smallholder farmers.
\end{abstract}

Keywords: conservation agriculture, supply side, demand side, tillage agriculture, no-till, sustainable intensification

\section{Introduction}

A scrutiny of agricultural production systems, their functioning and organization must consider how appropriate and sustainable the current agricultural paradigm is for the future for farmers, their communities and the society at large, and how environmentally sustainable it is? The agricultural supply side is generally analysed by mainstream scientists in terms of available resources and inputs for agriculture to meet future demand. Only more recently analyses have begun to address externalities of the production systems, such as environmental damages, as- sociated input factor efficiencies and system resilience against major external challenges. However, relatively rarely do mainstream researchers question the conventional agricultural paradigm regarding its appropriateness for the sustainable development agenda and the environmental challenges the world is facing. Equally, the delivery of ecosystem services by conventional agricultural has not been an area of serious mainstream research concern (MEA 2005; BedDington, J. 2011; LAL, R. and STEWART, R.A. 2013).

This article elaborates on the nature of the supply side of food and agriculture systems and discusses: How much food is being pro-

\footnotetext{
${ }^{1}$ University of Reading, UK. E-mail: amirkassam786@googlemail.com. Correspondent author.

${ }^{2}$ University of Evora, Portugal

${ }^{3}$ University of Cordoba, Spain.

${ }^{4}$ ACT Kenya
} 
duced currently? How much more do we need to produce to meet our future needs? How appropriate is the current production paradigm of tillage agriculture for meeting future food and agriculture needs? The article illustrates and discusses the inherent destructive nature of the conventional tillage agriculture itself in causing soil, land and environmental degradation, and its consequent inability to function at maximum output with efficiency and resilience, or to deliver ecosystem services. The article shows how sustainable production intensification can be and is being mobilized with the alternate paradigm of no-till CA that has been spreading in all continents since the 1990s (GoDDARD, T.M. et al. 2007; KASSAM, A. et al. 2009, 2013, 2015, 2016; Jat, R.A. et al. 2014; FARooQ, M. and SidDiQUe, K.H.M. 2015).

\section{Nature of the supply side}

Latest estimates from FAO suggest that the world needs to produce some 60 per cent more food to meet the demand of the expected global population of 9.2 billion at 2050 (FAO 2012). Recent FAO forecast indicates that this can be achieved if we can maintain an annual increase in food production globally at an average rate of 0.9 per cent, with a variation in regional rates from 0.3 per cent in Europe to 1.6 per cent in Africa (FAO 2014). In terms of the actual output of food, this corresponds to an increase in cereal production from 2.53 billion tons in 2014, from an area of 715 million hectares ( $3.54 \mathrm{t} / \mathrm{ha}$ ), to 3.28 billion tons in 2050, from an area of some 736 million hectares. This output equates to an average yield of $4.3 \mathrm{t} /$ ha to meet food, feed and biofuel demands as well as losses of some 40 per cent. If wastage was halved, the yield required would drop to 2.64 billion tons, corresponding to average yield of $3.44 \mathrm{t} / \mathrm{ha}$, and not much more than what the world agriculture is producing currently.

Reducing wastage is not going to be a simple matter because the issues involved are to do with our food habits and life styles as we become more affluent, urbanized and globalized, and the way the modern food system operates to store, process, and package and deliver food to meet demands. However, we can presume that there will be increasing pressure in the future from the consumers and governments to minimize wastage of food as cost of production and consumer prices rise, particularly in view to comply with the SDG 12 on responsible consumption and production.

To characterise the nature of the supply side, we have used cereal output required, and the corresponding net land area and average yield, to set the quantities involved. This is because cereals meet two-thirds of our calorie needs. Also, the proportion of net land area under cereals to annual noncereal crops is generally about 50:50 (BonTeFriedheim, C. and Kassam, A. 1994), and as cereal production increases, so does the non-cereal production. Thus the total agricultural land area required to meet global agricultural needs from annual cropping at 2050 will be some $763 \times 2=1.53$ billion hectares Assuming that there is additional need for land for permanent crops of various kinds of some 0.5 billion hectares would suggest a total net land area needed for annual and perennial crops of around 2 billion hectares.

Currently the total agricultural cropped area is 1.6 billion hectares. According to FAO (FAO/IIASA 2002; (FAO 2012), potential suitable agricultural land area globally (i.e. very suitable, suitable and moderately suitable land combined) is some 4.5 billion hectares. Thus, the net current cropped land area corresponds to some 36 per cent of the total global available suitable land area. In addition to the suitable agricultural land, there is some 2.7 billion hectares of marginal lands. We believe that this includes some 0.4 to 0.5 billion hectares of land area that was once suitable agricultural land but has been abandoned over the years (Dregne, H.E. and Chou, N.T. 1992; Pimentel, D. et al. 1995; Montgomery, D.R. 2007; Gibbs, H.K. and Salmon, J.M. 2015), particularly since the World War II, due to severe land degradation and erosion arising 
from the unsustainable way land is managed under the tillage-based agriculture in industrialized countries and in developing countries (Montgomery, D.R. 2007).

For the expected plateau population of 10 billion around 2100 and beyond, the total cereal required could be some 5 billion tones, if everyone were to demand some $500 \mathrm{~kg}$ per capita of cereals, which is the current level in Europe to meet food, feed and biofuel demands and the amount that is wasted. This equates to a yield of some $6.55 \mathrm{t} / \mathrm{ha}$ assuming no more area expansion in the net cropped area beyond 2050 (i.e. 763 million hectares) and no decrease in wastage, or $5.24 \mathrm{t} / \mathrm{ha}$ assuming 50 per cent decrease in wastage. Alternately, if we assumed an expansion of net land area for cereal cropping to 1 billion hectares, then the corresponding yields would be $5 \mathrm{t} / \mathrm{ha}$, assuming current levels of food wastage, or $4 \mathrm{t} / \mathrm{ha}$ assuming a 50 per cent decrease in food wastage.

Whichever way the future unfolds, it would seem that the total net area required to meet global food and agricultural needs would be between 2 and 2.5 billion hectares. Based on the assessments of land and water resources available, FAO and their collaborators have maintained that it should be possible to meet 2050 global food, feed, biofuel demand (including wastage) within realistic rates for land and water use expansion and yield development (FAO 2014).

\section{The 'hidden' reality and societal cost of conventional tillage agriculture}

While the quantities of yield and total output supply involved to support the food demand at 2050 appear agronomically doable, and there appears to be enough available land and water resources to support the required output, the reality on the ground on farms tells a different story.

The FAO future projections are based on assessments that assume the continued use of the tillage-based agricultural production systems (FAO 1978-1981, 2012, 2014; FAO/
IIASA 1984, 2002). However, the assessments do not explicitly take into account the resulting degradation and loss of crop and land productivity that has been occurring over the past years and which will continue in the future, leading to loss in productivity and marginalization and abandonment of agricultural lands. The marginal suitability category of land in the FAO assessments includes much of the degraded and abandoned agricultural land whose original agroecological suitability status is unknown.

Additionally, it is assumed that yield gaps can continue to be filled based on the current practice of intensive tillage and increased application of costly and excessive production inputs, assuming the same or even higher production increase rates than in the past. In other words, the paradigm assumed to meet future food demand in the future scenarios of FAO and their collaborators is the degrading 'business as usual' (FAO 1978-1981, 2012, 2014; FAO/IIASA 1984, 2002).

This 'more of the same' approach to intensification can no longer be considered to be sustainable economically, environmentally and socially anywhere including in the industrialized nations and in the emerging economies. In the low income countries, tillage agriculture based on the use of hoes and animal traction to pull simple ploughs leads to land degradation and loss of top soil to the point where land is eventually abandoned. Often, the lack of mineral fertilizers accelerates the loss in crop and land productivity.

Further, in many important high yield production areas the yields have reached a ceiling (Brisson, N. et al. 2010), with declining or even negative rates of yield increase. Conventional tillage-based production systems (sometime referred to as the Green Revolution (GR) agriculture paradigm) have generally become unsustainable for the future. This is because they have been causing land and ecosystem degradation, including loss of agricultural land, and loss of productivity and ecosystem and societal services (Montgomery, D.R. 2007; Goddard, T.M. et al. 2007; KASSAM, A. et al. 2009, 2013; 
Lindwall, C.W. and Sontag, B. 2010; BAsch, G. et al. 2012; JAT, R.A. et al. 2014; FAROoQ, M. and Siddique, K.H.M. 2015).

This GR approach does not seem to be going anywhere now even in the nations where it is claimed to have made an impact in the 1960s and the 1970s. For example, it is often stated that countries in Asia were the first to benefit from the GR, but the question is why did it not continue to spread? In fact, the conventional 'modern' approach to crop production intensification based on expensive intensive tillage, seeds, agrochemicals and energy is often not affordable by resource poor smallholder farmers, nor does it lend itself to socio-culturally inclusive development, given that all the individual production enhancing interventions of increased inputs must fit into some form of a 'neoliberal business model' in which it is assumed that farmers must purchase additional inputs from retail dealers in the supply chain who are buying those inputs from the wholesale dealers who are supplied by the manufacturer.

The point we are making is that the so called GR approach has led, particularly since World War II, to a paradigm for production intensification that is based on intensive tillage and the notion that more output can only come from applying more purchased inputs, and that farmers and their service providers and governments do not need to worry about the negative externalities that may arise as a result of the production practices being applied (Pretty, J. 2002; Beddington, J. 2011). Nor is there any concern being expressed in the conventional GR agriculture approach about agricultural land area continuing to be severely degraded and abandoned due to the negative impact of the conventional tillagebased production paradigm (KASSAM, A. et al. 2009 , 2013). Many areas, which in human history were the cradle of culture and intensive agriculture, are deserts today (MonTGOMERY, D.R. 2007).

Some 400 million hectaresof agricultural lands are reported to have been abandoned since the World War II due to severe soil and land degradation; and yields of staple cereals in industrialized regions appear to have stagnated under tillage agriculture (MONTGOMERY, D.R. 2007; Brisson, N. et al. 2010, GibBs, H.K. and SALMON, J.M. 2015). These are signs of unsustainability at the structural level in the society, and it is at the structural level, for both supply side and demand side, that we need transformed mind sets about production, consumption and distribution. Intensification under the GR paradigm globally has led to more intensive and aggressive mechanical soil tillage, input use and the application of economic models such as the specialization leading to extended monocropping. The result is more land degradation, erosion, pollution and vulnerability of agriculture related to extreme climatic events under a climate change scenario.

These practices in the tillage-based conventional production systems have all contributed, at all levels of development, to soil degradation and loss of agricultural land, decrease in attainable yields and input factor productivity, and excessive use of seeds, agrochemicals, water and energy, increase in cost of production, and poor resilience. They have also led to dysfunctional ecosystems, degraded ecosystem and societal services, including water quality and quantity, nutrient and carbon cycles, suboptimal water, nutrient and carbon provisioning and regulatory water services, and loss of soil and landscape biodiversity. They all constitute the unacceptable food, agricultural and environmental costs being passed on to the public and to the future generations.

This is why we say that if we are to: (i) mobilize greater crop and land potentials sustainably to meet future food, agriculture and environmental demands; (ii) maintain highest levels of productivity, efficiency and resilience ('more from less'); and (iii) rehabilitate degraded and abandoned agricultural land and ecosystem services, we need to replace the faltering production 'engine' - the conventional tillage-based production paradigm - and transform the food and agriculture systems that are built upon it. This transformation is now ongoing and needs to be acceler- 
ated (Goddard, T.M. et al. 2007; KAssam, A. et al. 2009, 2013, 2015, 2016; LindwALL, C.W. and Sontag, B. 2010; Jat, R.A. et al. 2014; Farooq, M. and Siddique, K.H.M. 2015).

\section{Replacing the faltering conventional tillage-based production engine with no-till CA}

Soil's productive capacity is derived from its many components (physical, biological, chemical, hydrological, climate) all of which interact dynamically in space and time within cropping systems and within agroecological and socio-economic environments. A productive soil is a living biological system and its health and productivity depends on managing it as a complex biological system, not as a geological entity. A regularly tilled soil, whether with a hand hoe or with a plough, eventually collapses and becomes compacted, cloddy and self-sealing. Instead of having 50 to 60 per cent air space in a healthy undisturbed soil, tilled soils have much lower volume of air space and no significant network of biopores. Of the 50 to 60 per cent pore space in a healthy soil, some 50 per cent can be filled with water, thus serving as a major buffer against climate variability. On the other hand, a regularly tilled soil would hold much less water due to its low pore volume and poor aggregate stability.

Scientific studies and empirical evidence worldwide have shown that the biology of the soil and all the biological processes along with the other chemical, hydrological and physical processes depend on soil organic matter content.

So the real secret of maintaining a healthy soil is to manage the carbon cycle properly, so that the soil organic matter content is always as high as possible above 2 per cent, that the soil is not disturbed mechanically to minimize the decomposition of organic matter, and that the soil surface is protected with a permanent layer of organic mulch cover which also serves as a substrate for soil microorganisms. In addition to maintain and support natural enemies of pests, a food web must be allowed to establish itself in the field, and this can only occur if there is a source of decomposing organic matter upon which to establish a food web above and below the ground surface, providing habitats for the natural enemies of pests.

As FAO's 'Save and Grow' approach shows (FAO 2011, 2016), to harness the conditions that are sufficient for achieving sustainable production intensification, agriculture must literally return to its roots and rediscover the importance of healthy soils, landscapes and ecosystems while conserving resources, enhancing natural capital and the flow of ecosystem and societal services at all levels - field, farm, community, landscape, territory and national (and beyond). The no-till production paradigm, known as CA (CA), is totally compatible with the above multi-dimensional goal as defined by its following three interlinked principles (www. fao.org/ag/ca):

1. No or minimum mechanical soil disturbance. Avoiding tillage and sowing seed or planting crops directly into untilled soil in order to: lessen the loss of soil organic matter and disruptive mechanical cutting and smearing of pressure faces, promote soil microbiological processes, protect soil structure and connected pores, avoid impairing movement of gasses and water through the soil, and promote overall soil health.

2. Maintaining a permanent mulch cover on the soil surface with growing plants and crop residue. Use crop residues (including stubbles) and cover crops to: protect the soil surface, conserve water and nutrients, supply organic matter and carbon to the soil system and promote soil microbiological activity to enhance and maintain soil health including structure and aggregate stability (resulting from glomalin production by mycorrhyza), and contribute to integrated weed, pest and nutrient management.

3. Diversification of species. Use of diversified cropping systems with crops in associations, sequences or rotations that will contribute to: diversity in rooting morphology, 
root compositions, enhanced microbiological activity, crop nutrition, crop protection, and soil organic matter build-up. Crops can include annuals, trees, shrubs, nitrogen-fixing legumes and pasture, as appropriate.

Implementing the above three principles using locally appropriate practices, along with other good practices of crop, soil, nutrient, water, pest, energy management, the above principles appear to offer entirely-appropriate solution, potentially able to slow or reverse productivity losses and environmental damages. They also offer a range of other benefits, which generally increase over time as new and healthier soil productivity equilibrium is established, including:

- Increase yields, farm production and profit, depending on the level of initial degradation and yield level (ECAF 2011; SOANE, B.D. et al. 2012; JAT, R.A. et al. 2015; FAROOQ, M. and Siddique, H.K.M. 2015; Li, H. et al. 2016; Kassam, A. et al. 2013, 2016).

- Up to 50 per cent less fertilizer required if already applying high rates, and greater nutrient productivity with increased soil organic matter level (SIMS, B. and KASSAM, A. 2015; Lalani, B. et al. 2016; Kassam, A. et al. 2016).

- Some 20-50 per cent less pesticides and herbicides required if already applying high rates, and greater output per unit of pesticide or herbicide. In the case where pesticides and herbicides are not used or available, integrated weed and pest management can achieve adequate pest and weed control with less labour requirements (Lindwall, C.W. and Sonntag, B. 2010; Lalani, B. et al. 2016; Kassam, A. et al. 2016).

- Up to 70 per cent less machinery, energy and labour costs. In manual production systems there can be a 50 per cent reduction in labour requirement as there is much less or no labour required for seedbed preparation and for weeding (SIMS, B. and Kassam, A. 2015; Freixial, R. and Carvalho, M. 2010).

- Decrease in soil erosion and water runoff (DERPSCH, R. 2003), increase water infiltra- tion, water retention and up to 40 per cent reduced water requirement and increased water productivity in rainfed and irrigated conditions (LANDERS, J. 2007; BASCH, G. et al. 2012; JAT, R.A. et al. 2015).

- Greater adaptability to climate change in terms of more stable yields, and lower impact of climate variability from drought, floods, heat and cold (Thierfelder, C. et al. 2015; Kassam, A. et al. 2016).

- Increased contribution to climate change mitigation from increased soil carbon sequestration, reduced greenhouse gas emissions, and decrease in the use of fossil fuel. Additionally, lower carbon and environmental footprint due to reduced use of manufactured inputs such as agrochemicals and machinery (ECAF 2011; Corsi, S. et al. 2012; Gonzalez-Sanchez, E.J. et al. 2012; Kassam, A. et al. 2009, 2013).

- Lower environmental cost to the society due to reduced levels of water pollution, and damage to infrastructure such as roads, bridges and riverbanks as well as water bodies due to reduced erosion and floods (Mello, I. and van RAIJ, B. 2006; ECAF 2011; LAUrent, F. et al. 2011; ANA 2011; ITAIPU 2011).

- Rehabilitation of degraded lands and ecoservices from all agricultural land under use as well as from abandoned agricultural land in which the eroded topsoil and the soil profile need to be rebuild (KAssam, A. et al. 2013).

- Greater opportunity for establishing large scale, community-based, cross-sectorial ecosystem service programmes such as the watershed services programme in the Parana Basin in Brazil, and the carbon offset trading scheme in Alberta, Canada (Mello, I. and van Raij, B. 2006; Haugen-Kozyra, K. and Goddard, T.M. 2009; Kassam, A. et al. 2011, 2013; LAURENT, F. et al. 2011; ANA 2011; ITAIPU 2011; CCC 2011).

The above benefits have now been documented on large and small farms throughout the world (GODDARD, T.M. et al. 2007; JAT, R.A. et al. 2015; Faroog, M. and Siddique, K.H.M. 2015; Kassam, A. et al. 2015, 2016). 
Consequently, increasingly greater attention is being paid to support the adoption and upscaling of CA by governments, international research and development organizations, national research and development bodies, NGOs and donors. They all see it as a viable option for sustainable production intensification to support local and national food security, poverty alleviation, especially of smallholders, improving ecosystem services, and reducing cost of production and minimizing land degradation. In 2013-2014, the global spread of CA was 157 million hectares of annual cropland, and since 2008-2009, the global area under CA has expanded at an annual rate of expansion of 10 million hectares. Some 50 per cent of the area is located in the developing regions and 50 per cent in the industrialized world.

Increasingly, CA is also seen to be complementary to System of Rice Intensification (SRI) because SRI performs best when aerobic soil conditions are maintained. Integrating SRI into rice crop management under CA increases significantly the water saving and yield potential. In practice, the SRI crop management method of planting in wide square spacing appears to benefit not only rice but many other crops including wheat, millet, tef, pulses and oilseeds, and vegetables (Uphoff, N. 2015).

\section{Concluding remarks}

In light of the above, we draw the following conclusions:

- Meeting 2050 food demand is agronomically doable. However, business as usual, and continuing to rely on conventional tillage-based farming system for further intensification of agricultural production, is not an option to meet future needs sustainably.

- For the farming communities, CA addresses the root causes of agricultural land degradation, sub-optimal ecological crop and land potentials or yield ceilings, and poor crop phenotypic expressions and yield gaps.
- CA is potentially applicable in most landbased agro-ecosystems and all cropping systems in rainfed and irrigated conditions.

- CA is increasingly seen as a real alternative and constraints to adoption are being addressed. It is now increasing at the annual rate of 10 million hectares and covered some 157 million hectares in 2013-2014.

- Land, water and climate constraints affect regions differently. All regions, but especially resource-poor regions, and areas affected by climate change would benefit immediately from CA.

- For developed regions, CA can improve profit, sustainability and efficiency at high yields with less degradation and more resistance to climatic shocks. For the high output farmer, CA offers greater efficiency (productivity) and profit, resilience and stewardship.

- For developing regions, CA offers greater output and profit to small and large farmers with less resources and land degradation. CA not only provides the possibility of increased crop yields for the low input smallholder farmer, it also provides a propoor rural and agricultural development model to support agricultural intensification in an affordable manner and an affordable way to adapt to climate change.

- CA is capable of rehabilitating degraded lands and ecosystem services on landbased production systems world-wide.

- Policy and institutional (including education and research) support, farmer organizations and champions are needed to mainstream the adoption of CA globally. As national economies expand and diversify, more people become integrated into the economy and are able to access food. However, for those whose livelihoods continue to depend on agriculture to feed themselves and the rest of the world population, the challenge is for agriculture to produce the needed food and raw material for industry with minimum harm to the environment and the society, and to produce it with maximum efficiency and resilience against abiotic and biotic stresses, including those arising from climate change. 
There is growing empirical and scientific evidence worldwide that the future global supplies of food and agricultural raw materials can be assured sustainably at much lower environmental and economic cost by shifting away from conventional tillage-based food and agriculture systems to no-till CA-based food and agriculture systems. To achieve this goal will require effective national and global policy and institutional support (including research and education).

\section{REFERENCES}

ANA 2011. Programa Produtor de Água (Programme for Water Producers ). http://www.ana. gov.br/ produagua/

Basch, G., Kassam, A., Friedrich, T., Santos, F.L., Gubiani, P.I., Calegari, A., Reichert, J.M. and Dos SAntos, D.R. 2012. Sustainable soil water management systems. In Soil Water and Agronomic Productivity. Eds.: LAL, R. and Stewart, B.A., Advances in Soil Science, CRC Press, 229-289.

Beddington, J. 2011. The Future of Food and Farming Futures: Challenges and choices for global sustainability. London, UK, Government Office for Science.

Bonte-Friedheim, C. and Kassam, A. 1994. Challenges to the Biophysical and Human Resource Base. In The Future of the Land: Mobilizing and Integrating Knowledge for Land Use Options. Eds.: Fresco, L.O., Stroosnijder, L., Bouma, J. and van Keulen, H., Chichester, UK, John Wiley, 337-384.

Brisson, N., Gate, P., Gouache, D., Charmet, G., Oury, F.X. and HuArD, F. 2010.Why are wheat yields stagnating in Europe? A comprehensive data analysis for France. Field Crops Research 119. 201-212.

CCC 2011. Specified Gas Emitters Regulation Results for the 2010 Compliance Year. Climate Change Central. http://carbonoffsetsolutions.climatechangecentral. com/policy-amp-regulation/alberta-offset-systemcompliance-a-glance/compliance-review-2010.

Corsi, S., Friedrich, T., Kassam, A., Pisante, M. and SÀ, J. DE M. 2012. Soil organic carbon accumulation and greenhouse gas emission reductions from $C A$ : a literature review. Integrative Crop Management 16. Rome, FAO.

Derpsch, R. 2003. Published with slight changes as a Special Publication by No-till on the Plains Inc., with the title "Understanding the Process of Water Infiltration". 2. (3): 1-4.

Dregne, H.E. and Chou, N.T. 1992. Global desertification dimensions and costs. In Degradation and Restoration of Arid Lands. Ed.: Dregne, H.E. Lubbock, Texas Technical University, USA, 73-92.
ECAF 2011. Making Sustainable Agriculture Real in CAP 2020: The Role of CA. Brussels, ECAF.

FAO 1978-1981. Report on the Agro-ecological Zones Project. Vol. 1. Methodology and results for Africa; Vol. 2. Results for Southwest Asia; Vol. 3. Methodology and results for South and Central America; Vol. 4. Results for Southeast Asia. World Soil Resources Report, No. 48. 1-4, Rome, FAO.

FAO 2011. Save and Grow: A policymaker's guide to the sustainable intensification of smallholder crop production. Rome, FAO.

FAO 2012. World Agriculture Towards 2030/2050: The 2012 Revision. Eds.: Alexandratos, N. and Bruinsma, J., Rome, FAO ESA Working Paper 12-30.

FAO 2014. World Cereal Production in 2016. http:// www.fao.org/worldfoodsituation/csdb/en/.

FAO 2016. Save and Grow in Practice: Maize, Rice and Wheat. FAO, Rome.

FAO/IIASA 1982. Potential population supporting capacities of lands in the developing world. Rome, FAO and IIASA.

FAO/IIASA 2002. Global agro-ecological assessment for agriculture in the $21^{\text {st }}$ Century: methodology and results. Rome-Laxenburg, FAO-IIASA.

Farooq, M. and Siddique, K.H.M. 2015. CA. Basel, Springer International.

Freixial, R. and Carvalho, M. 2010. Aspectos prácticos fundamentales en la implantación de la agricultura de conservación/siembra directa en el sur de Portugal. In Proceedings of the European Congress on CA: Towards Agro-Environmental Climate and Energetic Sustainability. Madrid, ECAF, 361-369.

Gibis, H.K. and Salmon, J.M. 2015. Mapping the world's degraded lands. Applied Geography 57. 12-21.

Goddard, T.M., Zoebisch, M., Gan, Y., Ellis, W., Watson, A. and Sombatpanit, S. eds. 2007. NoTill Farming Systems. Special Publication No. 3. Bangkok, World Association of Soil and Water Conservation (WASWAC).

GonzÁlez-SÁnchez, E.J, Ordoñez-Fernández, R., Carbonell-Bojollo, R., Veroz-Gonzalez, O. and GiL-RibES, J. 2012. Meta-analysis on atmospheric carbon capture in Spain through the use of CA. Soil and Tillage Research 122. 52-60.

Haugen-Kozyra, K. and Goddard, T.M. 2009. CA protocols for green house gas offsets in a working carbon markets. Paper presented at the IV World Congress on CA, 3-7 February 2009, New Delhi, India.

ITAIPU 2011. Cultivando Agua Boa (Growing Good Water). https://www.itaipu.gov.br/

Jat, R.A., Sahrawat, K.L. and Kassam, A. 2014. CA: Global Prospects and Challenges. Wallingford, UK, CABI.

Kassam, A., Basch, G., Friedrich, T., Shaxson, F., Goddard, T., Amado, T., Crabtree. B., Hongwen, L., Mello, I., Pisante, M. and Mкomwa, S. 2013. Sustainable soil management is more than what and how crops are grown. In Principles of Soil 
Management in Agro-ecosystems. Eds.: LAL, R. and Stewart, R.A. Advances in Soil Science, Boca Raton, CRC Press, 338-387.

Kassam, A., Friedrich, T., Derpsch, R. and Kienzle, J. 2015. Overview of the Worldwide Spread of CA. Field Actions Science Reports 8. http://factsreports. revues.org/3966

Kassam, A., Friedrich, T., Shaxson, T.F. and Pretty, J.N. 2009. The spread of CA: Justification, sustainability and uptake. International Journal of Agriculture Sustainability 7. (4): 292-320.

Kassam, A., Mкомwa, S. and Friedrich, T. 2016. CA for Africa: Building Resilient Farming Systems in a Changing Climate. Wallingford, UK, CABI.

Lal, R. and Stewart, R.A. eds. 2013. Principles of Soil Management in Agro-ecosystems. Advances in Soil Science. CRC Press.

Lalani, B., Dorward, P., Holloway, G. and Wauters, E. 2016. Smallholder farmers' motivations for using CA and the roles of yield, labour and soil fertility in decision making. Agricultural Systems 146. 80-90.

LANDERs, J. 2007. Tropical crop-livestock system in CA: The Brazilian experience. Integrated Crop Management Vol. 5. Rome, FAO.

Laurent, F., Leturce, G., Mello, I., Corbonnois, J. and Verdum, R. 2011. La diffusion du semis direct au Brésil, diversité des pratiques et logiques territoriales: l'exemple de la région d'Itaipu au Paraná. Confins 12. online, URL: http://confins. revues.org/7143

Li, H., Hea, J., Bharucha, Z.P., Lal, R. and Pretty, J. 2016. Improving China's food and environmental security with CA. International Journal of Agricultural Sustainability. http://dx.doi.org/10.1080/14735903.2 016.1170330.

Lindwall, C.W. and Sonntag, B. eds. 2010. Landscape Transformed: The History of Conservation Tillage and Direct Seeding. Knowledge Impact in Society. Saskatoon, University of Saskatchewan.
MEA 2005. Ecosystems and Human Well-Being: Synthesis. Millennium Ecosystem Assessment. Washington, DC, Island Press.

Mello, I. and van Raij, B. 2006. No-till for sustainable agriculture in Brazil. Proceedings of World Association of Soil and Water Conservation, P1. 49-57.

Montgomery, D.R. 2007. Dirt: The Erosion of Civilizations. Berkeley-Los Angeles, University of California Press.

Pimentel, D., Harvey, C., Resosudarmo, P., Sinclair, K., Kurz, D., McNaIr, M. et al. 1995. Environmental and economic costs of soil erosion and conservation benefits. Science 267. (5201): 1117-1123.

Pretty, J. 2002. Agri-Culture: Reconnecting People, Land and Nature. Earthscan.

Sims, B. and Kassam, A. 2015. East Anglia Branch visit to Tony Reynolds at Thurlby Grange Farm: No-till farming in the Lincolnshire fens. TAA Agriculture for Development 26. Winter, 51-52.

Soane, B.D., Ball, B.C., Arvidsson, J., Basch, G. and Roger-Estrade, F.M.J. 2012. No-till in northern, western and south-western Europe: A review of problems and opportunities for crop production and the environment. Soil and Tillage Research 118. 66-87.

Thierfelder, C., Bunderson, W.T., Jere, Z.D. and Mutenje, M. 2015. Development of CA (CA) systems in Malawi: Lessons learned from 2005 to 2014. Experimental Agriculture, Doi:10.1017/ S0014479715000265.

Uphoff, N. 2015. The System of Rice Intensification (SRI): Responses to Frequently Asked Questiond. SRI-Rice. Ithaca, USA, Cornell University. 
